\title{
Effect of Webinar educational program on Mothers' Knowledge and Practices regarding iron deficiency anemia among their Children
}

\author{
Hoda Wahid Amer ${ }^{1}$, Donia Elsaid Zaghamir ${ }^{2}$ \& Manal Mohamed Ayed ${ }^{3}$ \\ ${ }^{1 .}$ Lecturer of Pediatric Nursing College of Nursing, Misr University for Science \& Technology, Egypt \\ 2. Pediatric Nursing Department, Faculty of Nursing, PortSaid University, Egypt \\ 3. Assistant Professor of Pediatric Nursing Department, Faculty of Nursing, Sohag University, Egypt
}

\begin{abstract}
:
Online programs such as webinars play important role in improving people's knowledge and update their skills regarding diseases related to their children's health such as iron deficiency anemia (IDA). Aim: To evaluate the effect of using a webinar educational program on mothers' knowledge and practices regarding iron deficiency anemia among their children. Subjects and Methods: Design: A Quasi-Experimental design (one group pre/post design) was utilized in the current research. Setting: The study was carried out at Sohag City, Egypt. Subjects: This study was applied to a purposive sample of 350 mothers. Tools: A self-administered questionnaire was used; it includes four parts: Demographic data of the mother, mothers' knowledge about iron deficiency anemia, mothers' reported practice about iron deficiency anemia, and webinar characteristics through Zoom link. Results: It was observed that less than three-quarters of the studied mothers aged from 18 to 29 years with a mean age of 27.2 \pm 1.3 years. Most of the studied mothers didn't attend any courses before regarding iron deficiency anemia. It was noticed that webinars had a positive and significant effect on improving both knowledge and practices of mothers after implementation. Conclusion: Most of the mothers reported that online webinar educational programs had a positive effect on improving their knowledge and reported practices regarding iron deficiency anemia. Recommendations: A wellplanned educational program regarding other diseases among children could be introduced to their mothers through the webinar.
\end{abstract}

\section{Keywords: Children, Educational Program, Iron deficiency anemia, Mothers' knowledge \&practices, Webinar.}

\section{Introduction:}

Anemia was defined by the World Health Organization (WHO) as a public health issue that is classified into mild, moderate or severe if the prevalence ranges from 5 to $20 \%, 20$ to $40 \%$ or more than $40 \%$ correspondingly. The prevalence of anemia in WHO countries is moderate to severe where the affected percentage of young children and females is more than twenty percentages. It was found that the deficient iron availability in diet is the main cause of Iron Deficiency Anemia (IDA) in developing countries (Weiss et al., 2019).

Iron deficiency anemia can occur at all stages of life, it is more prevalent in young children and adolescents. Anemia is a nutritional problem, and it affects growth and cognition, work performance, and serious impact throughout the reproductive years of life and beyond (World Health Organization, 2015). Nutrition insufficiency is one of the leading causes of anemia in developing countries such as: deficiency of vitamin B12, riboflavin and folic acid in diet intake, also, lead toxicity, long-term diseases, infections (Shaw JG \& Friedman, 2011).

Infants and toddlers are considered to be highly vulnerable groups to IDA in the developed countries.
It was found in the United States that minimally 2.7 percentages of toddlers aging from 1 to 2 years are affected with IDA (Gupta et al., 2016). In 44 review studies that were carried out in nineteen European countries, it was stated that from two to twenty-five percentage of the infants aging from six to twelve months have IDA. The highest prevalence occurs in the infants that are given raw cow milk throughout their $1^{\text {st }}$ year, also, in socioeconomic deprived segment. The incidence rates of IDA ranges from three to forty-eight percentage in children group aging from twelve to thirty-six months (Eussen et al., 2015). In the low- \& middle-income countries, around forty percentages of the preschool children suffer from IDA (Armitage, \& Moretti, 2019).

Predisposing factors to iron deficiency anemia in developed countries are nutritional intake mistakes as deficit iron intake while breastfeeding after the $4^{\text {th }}$ month of life, administration of raw cow milk throughout child's $1^{\text {st }}$ year with volumes up to $500 \mathrm{ml}$ per day, absence of supplementary iron and plantbased diet (Parkin et al., 2016).

The world health organization suggested providing iron-containing micronutrient powder (MNPs) to children and toddlers aging from six to twenty-three 
months through which $12.5 \mathrm{mgs}$ of iron (in the form of coated ferrous fumarate) are provided per each sachet that is equivalent to $37.5 \mathrm{mgs}$ of ferrous fumarate salt or $62.5 \mathrm{mgs}$ of ferrous sulphate heptahydrate salt. The usage of sodium iron EDTA is unrecommended in children aging from six to twelve months. Other strategies recommend the administration of iron-containing diet in the form of MNPs with children from two to twelve years that includes $12.5 \mathrm{mgs}$ of iron for children aging from two to four years old and includes from 12.5 to $30 \mathrm{mgs}$ of iron for children aging from five to twelve years old (Zlotkin et al., 2018).

Supplementary food supported with iron-containing MNPs has been effective in reducing the risk for developing IDA in children aging less than 2 years. The MNPs have shown adverse effects such as changing normal gut flora along with the occurrence of intestinal inflammation causing diarrehea. Additionally, the advantages of such intervention and their effects on developmental needs of children are unknown. Consequently, the usage of MNPs cannot be used as alternative for meat (Wieringa, 2017).

The hematologic characteristics of iron deficiency anemia include decreased count of reticulocyte \& production index of reticulocyte (reticulocyte \% X hematocrit level/ normal hematocrit level X 0.5) (< $0.5 \%)$. Decreased indexes of red cell as Low mean corpuscular hemoglobin $(\mathrm{MCH})$, decreased count of red cells, Low mean corpuscular volume (MCV), Elevated red cell distribution width (RDW-CV) (>15\%), Low-normal hemoglobin A2 (1.5-3.2\%), Low hemoglobin content of reticulocytes (CHr) (<26pg), Low mean corpuscular hemoglobin concentration (MCHC), and Elevated platelet count (thrombocytosis) $\quad(>400,000 / \mu \mathrm{L}) \quad$ (Camaschella,

2015).

Before iron supplementation, it was recommended by the WHO to perform screening in children to target IDA if it was found that anemia is incident with percentage higher than 5. Also, American Academy of Pediatrics recommended performing IDA screening for 1 year old children as IDA is extremely prevalent at this stage and curable. Centers for Disease Control and Prevention recommended screening for children at high risk for developing IDA for example: child with low-iron intake formula, preterm infants, child who is fed with breastfeeding for 6 months without supplementary iron (Kemper et al., 2017).

Treatment of IDA should be started as soon as possible as children with IDA are at risk for developing ischemia along with the deterioration of their anemia, except on the treatment of the predisposing factor and iron storage in the bone marrow is restocked (Fabiano et al., 2018).
There are different iron treatments available for IDA, however, ferrous sulfate is the most commonly used iron formula all over the world. Other oral formulas such as ferric iron salt, carbonyl iron, ferric iron complexed with polysaccharides (iron polysaccharide complex, IPC), ferrous iron salts, iron complex with amino acids in the casein as iron protein succinylated and iron acetyl aspartylate, heme-iron polypeptides and chelates of iron with amino acids (Houston et al., 2018).

The 'webinar' has been defined as an internet workshop that involves a presentation, discussion, demonstration, or any other instructional event that allows participants from different places to hear and see the demonstrator and ask any question (Gegenfurtner et al., 2017). Due to these technological changes, people can easily communicate with all people who live in different parts of the world. People can view the latest updates through the internet with the help of mobile devices just by staying at home. It aids in the educational process of teaching \& learning. In recent years, webinars have increasingly grabbed attention for training purposes (Ebner \& Gegenfurtner, 2019).

The webinar was more effective in improving and developing participants' knowledge and practices which provide the attendees with some other incentives like live feedback forms, questions \& answers tools, and polls, and they provide an opportunity to prerecord the video or voice options (RAO, 2019). Webinar helps in creating chances to both demonstrator and attendees where they experience different levels of interaction of online help to exchange information in a real-time and twoway format and these opportunities are essentially different from other communication approaches the child care has been put directly onto parents, they try to participate in a webinar to gain knowledge about how to care with their children during emergencies and included early guidance that emphasizes on the provision of information to parents (Testers et al., 2019).

Mothers play an importance role in their children's life as they are the primary caregiver regarding iron deficiency anemia such as administer prescribed medications, as ordered, reduce fatigue by developing a schedule for daily activity and rest, and provide the children with foods rich in iron (organ and other meats, leafy green vegetables, molasses, beans). Prevent bleeding, prevent infection by assessing for local or systemic signs of infection, such as fever, chills, swelling, pain, and body malaise, daily hygiene, mouth care, and perineal care (Kemper et al., 2017).

Pediatric and community health nursing play an important role in providing education to mothers 
related to their children health regarding Iron deficiency anemia concerning some specific actions to maintain children's health such as encouraging consumption of foods rich with iron through healthy dietary change, providing nutritional education, providing education regarding treatment and prevention of parasitic infections, encouraging iron supplementation for children to prevent irondeficiency anemia, and improving iron status among children (World Health Organization, 2015). Hence, the researchers in this study wanted to measure the effect of using webinar educational programs on Mothers' knowledge and practices regarding iron deficiency anemia among children.

\section{Significance of the study:}

Iron deficiency anemia has become most frequent among children, and the WHO assumes that around 2 billion people (almost 25\% of world's population suffer from anemia and approximately half of them have IDA (Benoist et al., 2012). Iron deficiency anemia is accompanied with chronic impairments of neurocognition, learning disability \& alteration in the motor function. People with iron deficiency usually develop the following: restless leg syndrome and febrile seizures (Jang et al., 2019). In children, exhaustion and cold intolerance are symptoms accompanied by iron deficiency that are only relived after proper oral iron treatment (Howard \& Kamat, 2018).

Many benefits are associated with using online webinars such as accessibility', Affordability, Flexibility, Life- Long Learning, cost-effectiveness, and people can learn at their own pace. Thus, it can help to improve new skills and education can become life-long. Especially at the present the government pays great attention to online learning by using online webinars (Dhawan, 2020). So, it was very important to improve mothers' knowledge and practices regarding iron deficiency anemia through webinars as new methods of technology to maintain and promote health among their children because mothers who is the important one responsible for caring of their children at home.

Aim of the study:

To evaluate the effect of using webinar educational program on mothers' knowledge and reported practices regarding iron deficiency anemia among children through:

1. Assessing mothers' knowledge regarding iron deficiency anemia.

2. Assessing mothers' practices regarding iron deficiency anemia.

3. Investigate the relation between mothers' knowledge and practices regarding iron deficiency anemia.
4. Investigate the effect of webinar educational program on mothers' knowledge and practices regarding iron deficiency anemia

Research hypothesis:

Webinar educational program will have a positive effect on improving mothers' knowledge and practices regarding iron deficiency anemia among children.

\section{Subjects and Methods: \\ Research design:}

A Quasi-Experimental design (one group pre/post design) was utilized in the current research.

Setting:

The study was carried out at Sohag City, Egypt.

Subjects:

Purposive sample of 350 mothers was participated in the present study at Sohag City, through a Google form spreadsheet presented in Facebook and Whats App groups. All the studied mothers meet the following criteria:

Inclusion criteria of the studied mothers:

- Aged from 18-40 years

- Mothers of children aged from 1-12 years

- Educated mothers

Data collection tools:-

Tool: A self-administered questionnaire was used in the current study and developed by the researcher after reviewing related literature; (Jang et al., 2019, Ebner and Gegenfurtner, 2019, \&World Health Organization, (2015) it included four parts:

Part (1): It included information related to demographic data of the mothers such as age, educational level, residence, and occupation.

Part (2): It included information related to mothers' knowledge about iron deficiency anemia. It consisted of (15) multiple-choice question (MCQ) questions regarding:

- Definition of iron deficiency anemia

- Risk factors for iron deficiency anemia.

- Signs and symptoms of iron deficiency anemia

- Causes of iron deficiency anemia

- Prevention of iron deficiency anemia.

- Management and therapy of iron deficiency anemia

Scoring system:

One grade score was taken for the correct answer for each question, while the wrong answer was taken zero.

The total knowledge scores:-

- Knowledge level > 70\% was considered good knowledge

- From $50 \%$ to $70 \%$ was considered average or fair knowledge

- $<50 \%$ was considered poor knowledge

Part (3): It included information related to mothers' reported practice: It was developed by the researcher after review literature to assess reported practices of 
mothers with their children regarding iron deficiency anemia. It consisted of (10) multiple-choice question (MCQ) questions about how to improve dietary behaviors, iron supplementation, eating foods rich with iron, foods that increase iron absorption, and unhealthy habit prevent iron absorption.

\section{Scoring system:}

Reported practices items included MCQ form and the total score of practices score was 10 for the five items; the correct response was answered with 1and the incorrect response was answered with 0 .

The total reported practices scores system:-

- If mothers reported practices $\geq 60 \%$, they considered having satisfactory practices.

- If mothers' reported practices < 60\%, they considered having unsatisfactory practices

Part (4): Webinar characteristics through Zoom link: It included information related to webinar such as if the contents are enough, ideal length of the webinar, satisfaction toward webinar program as a method of learning if webinar improves mothers' knowledge and their reported practices, a suitable time for webinar attendance, advantages of the webinar, and disadvantages of the webinar.

Tools validity and reliability:

Face and content validity of the tool for clarity, comprehensiveness, and relevance was assessed by a board of five experts in pediatric nursing and community health nursing with more than ten years of experience in the field. The Reliability of the tool was assessed through Cronbach's alpha test $\alpha=0.86$.

\section{Operational Design:}

The operational design for this study included three phases named by; preparatory, implementation, and evaluation phase.

It was designed to evaluate the effect of using webinar educational program on mothers' knowledge and reported practices regarding iron deficiency anemia

\section{Preparatory phase:}

It was based on the assessment data was obtained during the developing online questionnaires from literature review about iron deficiency anemia knowledge and practices. Online booklet was developed by the researchers in Arabic language, printed out and given to them after implementing the program through Whats App group.

\section{Ethical considerations:}

Official permission was obtained through an issued letter from the Dean of Faculty of Nursing, Sohag University to conduct this study. An informed consent form was included on the first page of the online questionnaire that mothers cannot complete the questionnaire without this consent. The aim of the research was explained to all the mothers in the first part before starting the online questionnaire, the researchers informed the mothers that the study was voluntary; they were allowed to refuse or to participate. Moreover, they were assured that their information would be confidential and used for research purposes only.

\section{Pilot study:}

A pilot study was applied on $10 \%$ of the mothers (35 mothers) of children to test the clarity and the feasibility of the research process and needed time for data collection. No modifications were required in the pilot study. The pilot study sample was involved in the total sample.

\section{Implementation phase:}

At the beginning of the webinar, the researchers were introducing themselves to mothers and giving them brief information about the nature and purpose of the study. Assessment of each mother was done using Tool I as (pretest) before the webinar presentation to gather the basic data.

The zoom link was shared with the mothers of children aged from 1-12 years for a limited period from 30 October 2020 to 10 November 2020. This link was represented to invite participated mothers on Facebook and Whats app groups. On the first page of the online questionnaire, the mothers were informed about the aim and expected outcomes of the research study. The webinar was conducted from 8 to $9.30 \mathrm{pm}$. The average time spent for mothers' completion of the online questionnaire was about 15 minutes. Each mother involved in the study was informed about the aim of the study, the contents of the tools, and how to answer the online questionnaire.

The online questionnaire was used three times. The first time, it was used as a pretest for the assessment of mothers' knowledge about iron deficiency anemia and their reported practice. The second time, the same tool was used immediately at the end of the webinar presentation as a posttest and the third time after one week to evaluate the effect of webinar presentation on mothers' knowledge and reported practices regarding iron deficiency anemia and their immediate feedback about using the webinar to reinforce what they knew and correct mistakes.

During the webinar presentation, the host presenter chose to do one-way video broadcasting, so, the learners could sense the presence of the researchers. All mothers allowed two-way audio transmission, so, they could ask questions or clarify details at any time with audio or text chatting.

Session 1: All researchers began with a discussion about the program session's content then the learning outcomes of the next session. The session was performed by the researchers using the Arabic language that appropriate for women's understanding and they start to assess mothers' knowledge and 
practices regarding iron deficiency anemia among their children.

Session 2: The theoretical part contained knowledge about iron deficiency anemia such as definition of iron deficiency anemia, risk factors for iron deficiency anemia, signs and symptoms of iron deficiency anemia, causes of iron deficiency anemia, prevention of iron deficiency anemia, and management and therapy of iron deficiency anemia were explained. Other examples of the topics covered are the physiological changes that occurred by the disease. It was implemented through webinar, posters, about real food samples, and educational films.

Session 3: The practical part was contained information about reported practice regarding iron deficiency anemia and how to improve dietary behaviors, iron supplementation, eating foods rich with iron, foods that increase iron absorption, unhealthy habit prevent iron absorption, and doing required tests to ensure pregnancy efficiency. It was implemented through webinar presentation, online posters, and educational films.
Session 4: The researchers explained for mothers the importance of follow up for their children, importance of referral in sever problems for maintain care and prevent complications.

\section{The Evaluation phase:}

After implementing the webinar based program about iron deficiency anemia, evaluation was done using the same format of tool that was used in the pre-test to immediately evaluate the of research mothers' knowledge and after one week to mothers' knowledge and reported practices.

\section{Statistical analysis:}

Data analysis was performed using SPSS version 20. Data were presented using descriptive statistics in the form of frequencies and percentages for qualitative variables and mean and SDs for quantitative variables and mean values were compared using an independent t-test. Differences were considered significant at $\mathrm{p}$-values of less than 0.05. Chi-square test of significance was used to compare proportions between qualitative parameters.

\section{Results:}

Table (1): Distribution of the studied mothers regarding their demographic data $(\mathrm{N}=350)$

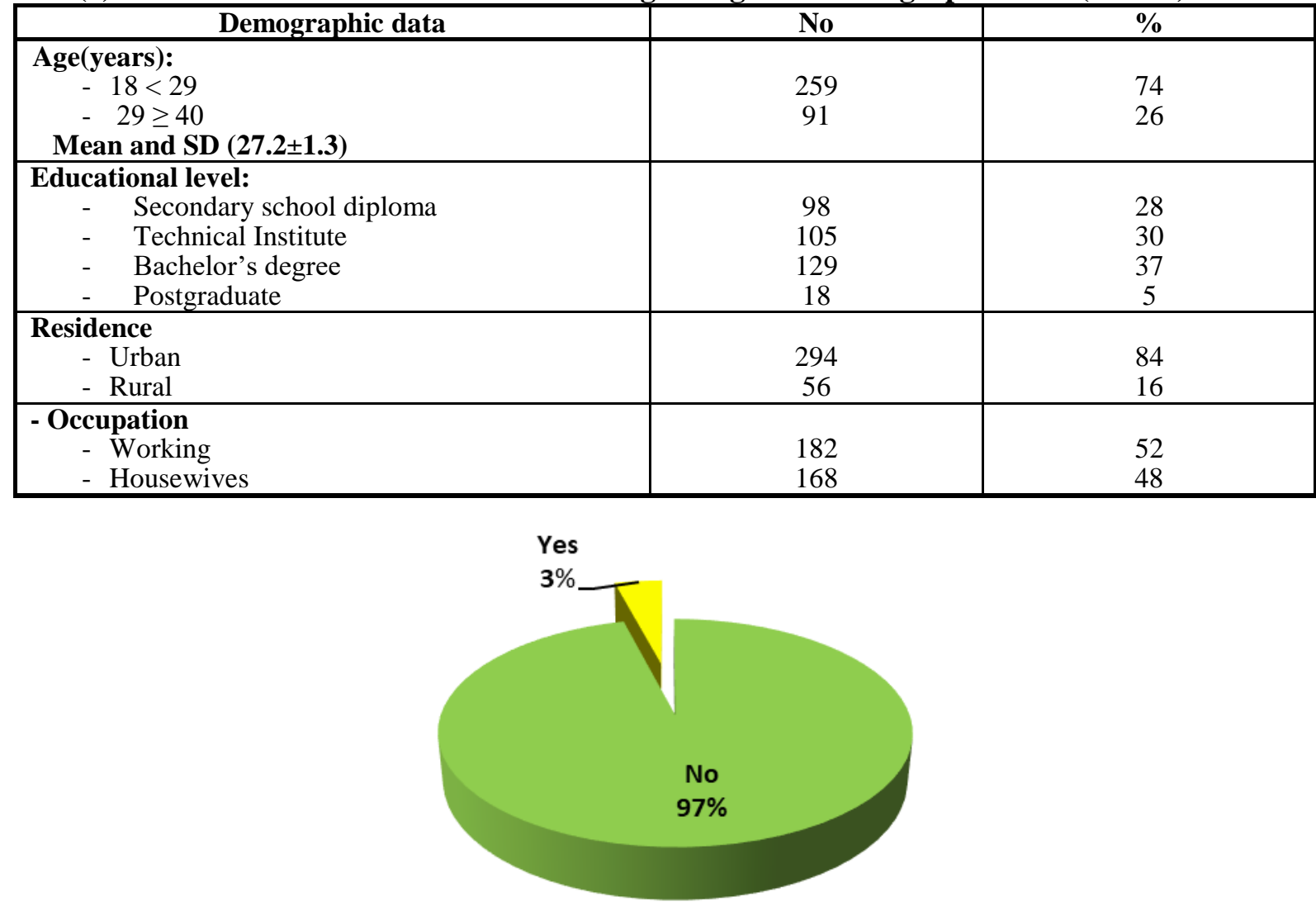

Figure (1): Distribution of the studied mothers according to attending courses before about iron deficiency anemia. 
Table (2): Mean differences between pre, post immediate, and post one week of webinar implementation regarding knowledge of the studiedmothers about iron deficiency anemia $(\mathbf{n}=350)$.

\begin{tabular}{|l|c|c|c|c|c|c|}
\hline \multicolumn{1}{|c|}{ Variable } & Score & $\begin{array}{c}\text { Before } \\
\text { webinar }\end{array}$ & $\begin{array}{c}\text { Immediately after } \\
\text { webinar }\end{array}$ & $\begin{array}{c}\text { One week after } \\
\text { the webinar }\end{array}$ & X2 & P-value \\
\hline $\begin{array}{l}\text { Definition of iron } \\
\text { deficiency anemia }\end{array}$ & 2 & $0.48 \pm 0.49$ & $1.22 \pm 0.37$ & $1.20 \pm 0.26$ & 15.3 & $<0.001 * *$ \\
\hline $\begin{array}{l}\text { Risk factors for iron } \\
\text { deficiency anemia }\end{array}$ & 2 & $0.55 \pm 0.78$ & $1.33 \pm 0.43$ & $1.32 \pm 0.23$ & 10.04 & $<0.001 * *$ \\
\hline $\begin{array}{l}\text { Signs and symptoms of iron } \\
\text { deficiency anemia }\end{array}$ & 2 & $0.57 \pm 0.39$ & $1.22 \pm 0.52$ & $1.21 \pm 0.32$ & 13.8 & $<0.001 * *$ \\
\hline $\begin{array}{l}\text { Causes of iron deficiency } \\
\text { anemia }\end{array}$ & 2 & $0.49 \pm 0.87$ & $1.41 \pm 0.62$ & $1.31 \pm 0.42$ & 20.5 & $<0.001 * *$ \\
\hline $\begin{array}{l}\text { Diagnosis of iron } \\
\text { deficiency anemia }\end{array}$ & 2 & $0.66 \pm 0.53$ & $1.72 \pm 0.21$ & $1.62 \pm 0.11$ & 12.7 & $<0.001 * *$ \\
\hline $\begin{array}{l}\text { Prevention of iron } \\
\text { deficiency anemia }\end{array}$ & 3 & $1.09 \pm 0.27$ & $2.18 \pm 0.39$ & $2.10 \pm 0.29$ & 17.4 & $<0.001 * *$ \\
\hline $\begin{array}{l}\text { Management and therapy } \\
\text { of iron deficiency anemia }\end{array}$ & 2 & $0.36 \pm 0.43$ & $1.37 \pm 0.53$ & $1.32 \pm 0.23$ & 13.02 & $<0.001 * *$ \\
\hline Total knowledge & 15 & $4.45 \pm 0.89$ & $13.05 \pm 0.59$ & $12.40 \pm 0.87$ & 22.78 & $<0.001 * *$ \\
\hline
\end{tabular}

(*) Statistically Significant at $p \leq 0.001$

Table (3): Mean differences between pre and post one week of webinar implementation regarding practices of the studiedmothers about iron deficiency anemia $(\mathbf{n}=350)$.

\begin{tabular}{|c|c|c|c|c|c|}
\hline Variables & Score & Before webinar & $\begin{array}{c}\text { One week after } \\
\text { the webinar }\end{array}$ & $\begin{array}{c}\text { Paired } \\
\text { t-test }\end{array}$ & P-value \\
\hline $\begin{array}{l}\text { Proper and health dietary } \\
\text { behaviors }\end{array}$ & 2 & $.61 \pm .46$ & $1.64 \pm .32$ & 14.7 & $<0.001 * *$ \\
\hline Iron supplementation & 2 & $.33 \pm .50$ & $1.27 \pm .26$ & 13.2 & $<0.001 * *$ \\
\hline Eating foods rich with iron & 2 & $. .72 \pm .46$ & $1.79 \pm .23$ & 14.2 & $<0.001 * *$ \\
\hline Foods that increase iron absorption & 2 & $.72 \pm .34$ & $1.32 \pm .49$ & 16.3 & $<0.001 * *$ \\
\hline $\begin{array}{llll}\begin{array}{l}\text { Unhealthy } \\
\text { absorption }\end{array} & \text { habit } & \text { prevent } & \text { iron } \\
\end{array}$ & 2 & $.54 \pm .59$ & $1.58 \pm .39$ & 12.7 & $<0.001 * *$ \\
\hline
\end{tabular}

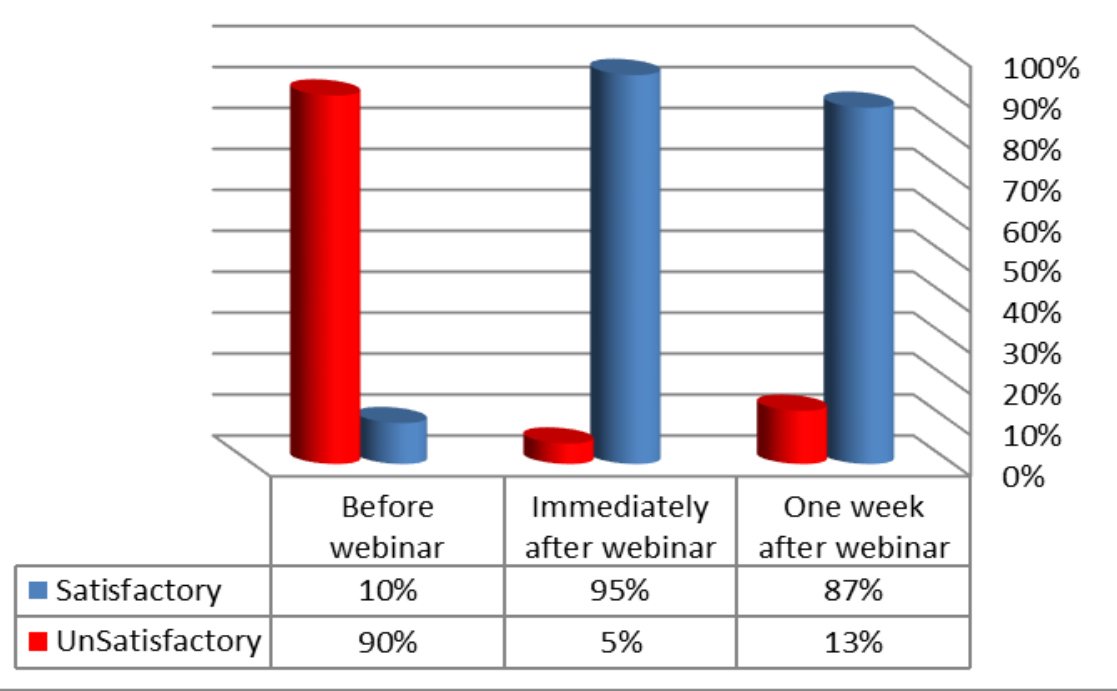

Figure (2): Distribution of the studiedmothers regarding reported practices about iron deficiency anemia pre, post immediate, and post one week of webinar implementation $(n=350)$. 
Table (4): Frequency and percentage distribution of the studied mothers regarding their feedback about webinar presentation characteristics $(n=350)$

\begin{tabular}{|c|c|c|}
\hline Webinar characteristics & No & $\%$ \\
\hline $\begin{array}{l}\text { Are webinar contents enough: } \\
-\quad \text { Yes } \\
-\quad \text { No }\end{array}$ & $\begin{array}{c}340 \\
10\end{array}$ & $\begin{array}{c}97 \\
3\end{array}$ \\
\hline $\begin{array}{l}\text { The ideal length of the webinar } \\
-\quad 60 \text { minutes } \\
-\quad 45 \text { minutes } \\
-\quad 30 \text { minutes }\end{array}$ & $\begin{array}{c}18 \\
318 \\
14\end{array}$ & $\begin{array}{c}5 \\
91 \\
4\end{array}$ \\
\hline $\begin{array}{l}\text { Satisfaction toward webinar program as a method of learning } \\
-\quad \text { Yes } \\
-\quad \text { No }\end{array}$ & $\begin{array}{c}332 \\
18\end{array}$ & $\begin{array}{c}95 \\
5\end{array}$ \\
\hline $\begin{array}{l}\text { Webinar help improve knowledge and reported practices } \\
-\quad \text { Yes } \\
-\quad \text { No }\end{array}$ & $\begin{array}{c}350 \\
0\end{array}$ & $\begin{array}{c}100 \\
0\end{array}$ \\
\hline $\begin{array}{c}\text { Suitable time for webinar attendance: } \\
-\quad \text { In the morning } \\
-\quad \text { In the afternoon } \\
-\quad \text { At night }\end{array}$ & $\begin{array}{c}10 \\
42 \\
298\end{array}$ & $\begin{array}{l}3 \\
12 \\
85\end{array}$ \\
\hline $\begin{aligned} \text { (*) Advantages of the webinar: } \\
\text { - } \quad \text { Active participation } \\
\text { - } \quad \text { A chance for live chat among participants. } \\
\text { - } \quad \text { Attendance at any place. } \\
\text { - } \quad \text { Share the screen among participants. }\end{aligned}$ & $\begin{array}{l}332 \\
329 \\
326 \\
322\end{array}$ & $\begin{array}{l}95 \\
94 \\
93 \\
92\end{array}$ \\
\hline $\begin{array}{l}\text { Disadvantages of webinar } \\
\text { - } \quad \text { Interruption of internet } \\
\text { - A large sample can interfere with the inability of participants to } \\
\text { attend the webinar }\end{array}$ & $\begin{array}{c}336 \\
14\end{array}$ & $\begin{array}{c}96 \\
4\end{array}$ \\
\hline
\end{tabular}

(*) There is more than one answer

Table (5): Comparison of total knowledge and reported practices among the studied mothers regarding iron deficiency anemia pre, post immediate, and post one week of webinar implementation $(\mathbf{n}=350)$.

\begin{tabular}{|c|c|c|c|c|c|c|c|}
\hline \multirow[t]{2}{*}{ Item } & \multicolumn{2}{|c|}{ Before webinar } & \multicolumn{2}{|c|}{$\begin{array}{c}\text { Immediately after } \\
\text { webinar }\end{array}$} & \multicolumn{2}{|c|}{$\begin{array}{c}\text { One week after } \\
\text { the webinar }\end{array}$} & \multirow[t]{2}{*}{ t-test P1 } \\
\hline & No & $\%$ & No & $\%$ & No & $\%$ & \\
\hline \multicolumn{8}{|l|}{ Knowledge } \\
\hline Poor & 315 & 90 & 0 & 0 & 0 & 0 & \multirow{3}{*}{$\begin{array}{c}27.60 \\
(0.001)^{*}\end{array}$} \\
\hline Fair & 35 & 10 & 14 & 4 & 32 & 9 & \\
\hline Good & 0 & 0 & 336 & 96 & 318 & 91 & \\
\hline \multicolumn{8}{|l|}{ Practices } \\
\hline Satisfactory & 35 & 10 & 332 & 95 & 308 & 88 & \multirow{2}{*}{$\begin{array}{c}25.53 \\
(0.001)^{*}\end{array}$} \\
\hline unsatisfactory & 315 & 90 & 18 & 5 & 42 & 12 & \\
\hline
\end{tabular}

(*) Statistically Significant at $p \leq 0.001$

Table (6): Correlation between overall scores of studied mothers' knowledge and reported practices regarding iron deficiency anemia pre and post one week of webinar implementation

\begin{tabular}{|l|c|c|c|c|}
\hline \multirow{2}{*}{ Total knowledge score } & \multicolumn{4}{|c|}{ Total reported practices score } \\
\cline { 2 - 5 } & \multicolumn{3}{|c|}{ Pre-program } & \multicolumn{2}{c|}{ Post-program } \\
\cline { 2 - 5 } & $\mathbf{R}$ & P value & r & P value \\
\hline Pre-program & $\mathbf{0 . 1 3 4}$ & $>\mathbf{0 . 0 5}$ & - & - \\
\hline Post-program & - & - & $\mathbf{0 . 7 6 3}$ & $\mathbf{0 . 0 0 0} * *$ \\
\hline
\end{tabular}

Statistical significance $P$ : $<0.05$. 
Table (1): Represented the demographic data of the studied mothers. It was observed that $(74 \%)$ of the studied mothers were aged from 18 to 29 years with a mean age of $27.2 \pm 1.3$ years. regarding educational level, more than a quarter $(37 \%)$ of them had bachelor's degree, $(84 \%)$ were living in urban areas and $(52 \%)$ of them were working.

Figure (1): Showed the previous attendance courses regarding iron deficiency anemia of the studied mothers. It was noticed that $(97 \%)$ of the studied mothers didn't attend any courses before.

Table (2): Revealed that highly statistically significant differences were observed between mothers' knowledge regarding iron deficiency anemia pre, post immediate, and post one week of webinar implementation. Also, these differences indicated improvement of mothers' knowledge regarding iron deficiency anemia pre, post immediate, and post one week of webinar implementation and the positive effect of the webinar implementation.

Table (3): It observed from that a highly statistically significant difference and improvements was detected between mothers' reported practices regarding iron deficiency anemia and post one week of webinar implementation including proper and healthy dietary behaviors, iron supplementation, eating foods rich with iron, foods that increase iron absorption, and unhealthy habit prevent iron absorption ( $\mathrm{p}<0.001 * *)$.

Figure (2): It was clarified from that, (90\%) of mothers had unsatisfactory total reported practice scores pre-webinar health program implementation regarding iron deficiency anemia which improved and become $(95 \%)$ of them had satisfactory total reported practice scores post-implementation of the webinar, which mean the improvement of their practice and positive effect of the webinar.

Table (4): Showed the distribution of the studied mothers regarding their feedback about webinar characteristics. It was clarified that most (97\%) of the studied mothers reported that webinar contents were enough. Regarding the ideal length of the webinar, $(91 \%)$ of them reported that the ideal length was 45 minutes and (95\%) of them were satisfied with the webinar. Also, all mothers (100\%) said that webinar has improved their knowledge and practices. Regarding suitable time for attending webinar (85\%) of the studied mothers reported suitable time was at night. Concerning the advantages of the webinar, the highest percentage of mothers $(95 \%)$ reported that it allows their active participation, and (96\%) of them said that the disadvantage of the webinar was an interruption of the internet.

Table (5): Demonstrated the comparison of total knowledge and reported practices among the studied mothers regarding iron deficiency anemia pre, post immediate, and post one week of webinar implementation. It was observed that $(90 \%)$ of the studied mothers had poor knowledge before webinar presentation, there are improvements of knowledge after implementation of the program where $(96 \%)$ of them immediately after the webinar implementation had good knowledge and $(91 \%)$ of them had good knowledge after one week of webinar implementation. Also, it was noticed that webinar implementation had a significant positive effect on improving knowledge of studied mothers immediately after and post one week of webinar implementation $(\mathrm{P}=0.001)$. Concerning the level of practices, it was observed that $(90 \%)$ of the studied mothers had unsatisfactory reported practices regarding iron deficiency anemia before webinar implementation compared with $(95 \%)$ of them immediately after and $(88 \%)$ after one week of webinar implementation had satisfactorily reported practices. There was a significant effect on improving reported practices of studied mothers immediately after and after one week of webinar implementation $(\mathrm{P}=0.001)$.

Table (6): Revealed a positive correlation between studied mothers' knowledge and practices regarding iron deficiency anemia pre, post immediate, and post one week of webinar implementation.

\section{Discussion:}

Iron deficiency anemia (IDA) occurred as a result of low dietary intake, blood loss resulting in loss of iron, iron absorption problems, and other medical diseases (National Heart, Lung, \& Blood Institute, 2019). It was observed after collecting data that the subjects did not have enough knowledge about iron deficiency anemia before the webinar implementation. By investigating the mothers' knowledge and their reported practices pre and post the webinar implementation, it was noticed that there was an improvement in their knowledge and reported practices compared to before the webinar implementation. Hence, the researchers aimed to measure the effect of using webinar educational program on mothers' knowledge and reported practices regarding iron deficiency anemia among their children.

Findings of the current study indicated that most of the studied mothers didn't attend any courses before. This has reflected the importance of the present study and allowed mothers to be engaged in such webinars to improve their knowledge and practices about iron deficiency anemia.

Findings of the present study highlighted that, there were differences between mothers' knowledge scores which indicated improvement in knowledge regarding iron deficiency anemia in pre, post immediate, and post one week of webinar implementation. This has reflected the positive 
effect of the webinar implementation. This result is in the same line with Abu-Baker et al., (2021) who conducted study in Jordan about "The impact of nutrition education on knowledge, attitude, and practice regarding iron deficiency anemia among female" and stated that educational intervention is an effective method to increase mothers' awareness regarding iron deficiency anemia.

Results of the present study indicated that a highly statistically significant difference and improvements was detected between mothers' reported practices regarding iron deficiency anemia and post one week of webinar implementation. This reflects success of webinar based program and it was efficient to equip mothers with enough knowledge that lead to good practices.

Findings of the present study highlighted that, most of the mother had satisfactory total reported practice scores post-implementation of the webinar regarding iron deficiency anemia. This means and confirms the importance of program implementation through webinar about current topic in the community.

Findings of the current study found that most of the studied mothers reported that the ideal length of the webinar was 45 minutes. This is explained by that attendance webinar for long time causes loss of concentration. These results are matched with Gegenfurtner, et al., (2020) who stated in their study about Evaluating webinar-based training: a mixed-methods study of trainee reactions toward digital web conferencing that trainer preferred webinars that are no longer in time.

Results of the current study revealed that the webinars had a positive, significant relation and effect on improving both knowledge and reported practices of mothers after implementation. This is explained by the beneficial effects of the educational program about the topic. These results were concurrent with a study conducted by Lotfi et al., (2015) and pointed out that in Morocco about assessment of nutritional knowledge of athletes in Kenitra and revealed that the nutritional knowledge score (NKS) was relatively low and a significant difference and improvement after nutritional education was observed. Also, previous studies were done in India (Singh et al., 2019) and Ethiopia (Gebreyesus et al., 2019) reported similar findings. This highlights the need to educate mothers about IDA.

Results of the current study supported the hypothesis and the aim of the study that implementing educational program through webinar effectively improves the knowledge and reported practices regarding IDA among studied mothers.

These results agreed with the researches that were done in Egypt and Palestine by Ibrahim \& El-
Lassy, (2013) who studied "Nutritional Program Based on Dietary Pattern and Iron Deficiency Anemia-Related Knowledge Among Egyptian Preparatory School Girls" and Jalambo et al., (2017) who studied "Improvement in knowledge, attitude and practice of iron deficiency anemia among iron-deficient female adolescents after nutritional educational intervention" and they found that educational interventions showed significant score improvements from pretests to posttests.

Also, this is similar to studies conducted by (Gopal \& Chand, (2017) who studied the effectiveness of structured teaching program on knowledge regarding prevention of anemia among adolescent girls in A selected senior secondary schools of Bharatpur and Chaluvaraj \& Satyanarayana, (2018) who carried out a study about "Change in knowledge, attitude and practice regarding anemia among high school girls in rural Bangalore" and they found that educational interventions and showed significant improvement in scores.

Bhaumik \& Priyadarshini, (2020) reported that webinars are very important for people so that they can develop and share their own knowledge, experiences and practices.

This reflects the effectiveness of webinars in improving knowledge and practices. These results agree with the results conducted by Gegenfurtner, et al., (2020) who stated that webinars were more effective in promoting achievement than traditional face-to-face seminars. In contrast, this result was not similar to Ebner \& Gegenfurtner, (2019) study who reported that webinars are not always successful in promoting learning outcomes in comparison to face-to-face classrooms. This reflects the urgent need for the development and implementation of interventions through a webinar that maintain child health promotion on the prevention of illness.

\section{Conclusion:}

Depending on the findings of the current study and research hypotheses, it was concluded that the knowledge level has been improved and satisfactory reported practices were found among the majority of the pregnant women after the implementation of the webinar educational program. Most of the mothers reported that online webinar educational program had a positive effect on improving their knowledge and reported practices regarding iron deficiency anemia. This was confirmed by highly significant differences between before/immediately after webinar evaluation about knowledge and practices regarding iron deficiency anemia 


\section{Recommendations:}

A well-planned educational program regarding other diseases among children could be introduced to their mothers through webinar. Future research about the effect of webinar on improving skills and practices regarding other topics

\section{Limitations of the study:}

The current study had one limitation, there was sampling bias being conducted only with educated mothers that have internet access which did not represent and reflect the whole mothers.

\section{References:}

- Abu-Baker, N., Eyadat, A., \& Khamaiseh, A. (2021): The impact of nutrition education on knowledge, attitude, and practice regarding iron deficiency anemia among female adolescent students in Jordan. Heliyon, 7(2), e06348.

- Armitage, A., \& Moretti, D. (2019): The importance of iron status for young children in low-and middle-income countries: a narrative review. Pharmaceuticals, 12 (2), 59.

- Benoist, B., Cogswell, M., Egli, I., \& McLean, E. (2012): Worldwide prevalence of anaemia 19932005; WHO Global Database of anaemia.

- Bhaumik, R., \& Priyadarshini, A. (2020): Ereadiness of senior secondary school learners to online learning transition amid COVID-19 lockdown. Asian Journal of Distance Education, 15(1), 244-256.

- Camaschella, C. (2015): Iron deficiency: new insights into diagnosis and treatment. Hematology, 2015(1), 8-13.

- Chaluvaraj, T., \& Satyanarayana, P. (2018): Change in knowledge, attitude and practice regarding anaemia among high school girls in rural Bangalore: An health educational interventional study. Natl J Community Med, 9, 358-62.

- Dhawan, S. (2020): Aprendizaje en línea: una panacea en tiempos de crisis de COVID19. Revista de sistemas de tecnología educativa, 49(1), 5-22.

- Ebner, C., \& Gegenfurtner, A. (2019): Learning and satisfaction in webinar, online, and face-toface instruction: a meta-analysis. In Frontiers in Education (Vol. 4, p. 92). Frontiers.

- Eussen, S., Alles, M., Uijterschout, L., Brus, F., \& Van Der Horst-graat, J. (2015): Iron intake and status of children aged 6-36 months in Europe: a systematic review. Annals of Nutrition and Metabolism, 66(2-3), 80-92.

- Fabiano, A., Brilli, E., Fogli, S., Beconcini, D., Carpi, S., Tarantino, G., \& Zambito, Y. (2018): Sucrosomial ${ }^{\circledR}$ iron absorption studied by in vitro and ex-vivo models. European Journal of Pharmaceutical Sciences, 111, 425-431.

- Gebreyesus, S., Endris, B., Beyene, G., Farah, A., Elias, F., \& Bekele, H. (2019): Anaemia among adolescent girls in three districts in Ethiopia. BMC public health, 19(1), 1-11.

- Gegenfurtner, A., Spagert, L., Schwab, N., Oswald, A., Weng, G., Resch, C. \& Bomke, C. (2017): LernCenter: ein Konzept für die Digital isierung berufsbegleitender Weiterbildungen an Hochschulen.

- Gegenfurtner, A., Zitt, A., \& Ebner, C. (2020): Evaluating webinar-based training: a mixed methods study of trainee reactions toward digital web conferencing. International Journal of Training and Development, 24(1), 5-21.

- Gopal, R., \& Chand, T. (2017): A study to assess the effectiveness of structured teaching programme on knowledge regarding prevention of anemia among adolescent girls in A selected senior secondary schools of Bharatpur. Int. J. Sustain. Strat. Manag. 4 (3), 192-197.

- Gupta, P., Perrine, C., Mei, Z., \& Scanlon, K. (2016): Iron, anemia, and iron deficiency anemia among young children in the United States. Nutrients, 8(6), 330.

- Houston, B., Hurrie, D., Graham, J., Perija, B., Rimmer, E., Rabbani, R. \& Zarychanski, R. (2018): Efficacy of iron supplementation on fatigue and physical capacity in non-anaemic irondeficient adults: a systematic review of randomised controlled trials. BMJ open, 8(4).

- Howard, H., \& Kamat, D. (2018): Restless legs syndrome in children. Pediatric annals, 47(12), e504-e506.

- Ibrahim, E., \& El-Lassy, R. (2013): Nutritional program based on dietary pattern and iron deficiency anemia-related knowledge among Egyptian preparatory school girls.

- Jalambo, M., Sharif, R., Naser, I., \& Karim, N. (2017): Improvement in knowledge, attitude and practice of iron deficiency anaemia among irondeficient female adolescents after nutritional educational intervention. Global Journal of Health Science, 9(7), 15-23.

- Jang, H., Yoon, H., \& Lee, E. (2019): Prospective case control study of iron deficiency and the risk of febrile seizures in children in South Korea. BMC pediatrics, 19(1), 1-8.

- Kemper, A., Fan, T., Grossman, D., \& Phipps, M. (2017): Gaps in evidence regarding iron deficiency anemia in pregnant women and young children: summary of US Preventive Services Task Force recommendations. The American journal of clinical nutrition, 106(suppl_6), 1555S-1558S. 
- Lotfi, Z., Youssef, A., \& Rachid, S. (2015): Assessment of nutritional knowledge of athletes in Kenitra city, Morocco. Am. J. Innov. Res. App. Sci. 1: 209-213.

- National Heart, Lung, \& Blood Institute (2019): Iron-deficiency Anemia. Retrieved August 15th, from: https://www.nhlbi.nih.gov/healthtopics/iron-deficiencyanemia.

- Parkin, P., DeGroot, J., Maguire, J., Birken, C., \& Zlotkin, S. (2016): Severe iron-deficiency anaemia and feeding practices in young children. Public health nutrition, 19(4), 716-722.

- Roa, P. (2019): The influence of webinars in developing teaching skills of the English language teachers: A comprehensive in ELT. ISSN: 23952636 (P); 2321-3108(O) Vol.7.Issue 4.

- Shaw, J., \& Friedman, J. (2011): Iron deficiency anemia: focus on infectious diseases in lesser developed countries. Anemia, 2011.

- Singh, M., Rajoura, O., \& Honnakamble, R. (2019): Anemia-related knowledge, attitude, and practices in adolescent schoolgirls of Delhi: A cross-sectional study. International Journal of Health \& Allied Sciences, 8(2), 144-144.

- Testers, L., Gegenfurtner, A., van Geel, R., \& Brand-Gruwel, S. (2019): From monocontextual to multicontextual transfer: organizational determinants of the intention to transfer generic information literacy competences to multiple contexts. Frontline Learning Research, 7(1), 23-42.

- Weiss, G., Ganz, T., \& Goodnough, L. (2019): Anemia of inflammation. Blood; 133(1):40-50.

- Wieringa, F. (2017) Micronutrient powders to combat anemia in young children: does it work? BMC medicine, 15(1), 1-3.

- World Health Organization (2015): Prevention of Iron Defciency Anemia in Adolescents. Role of Weekly Iron and Folic Acid Supplementation, http://www.searo.who.int/entity/child adolescent/documents/sea cah 2/en/.

- Zlotkin, S., PenaRosas, J.P., \& Velazquez, F.B. (2018): Multiple Micronutrient Powders for Pointof-Use Fortification of Foods Consumed by Infants and Children 6-23. WHO Department of Nutrition for Health and Development, Months of Age and Children Aged 2- 12Years. 29. https://www.who.int/selection_medicines/com mittees/expert/22/applications/s10.1_micronutrient -powders.pdf?ua=1. 